\title{
Ten steps to 4C/ID: training differentiation skills in a professional development program for teachers
}

\author{
Jimmy Frerejean ${ }^{1}$ (D) Marieke van Geel ${ }^{2} \cdot$ Trynke Keuning $^{2,3} \cdot$ Diana Dolmans $^{1}$. \\ Jeroen J. G. van Merriënboer ${ }^{1} \cdot$ Adrie J. Visscher $^{2}$
}

Received: 27 January 2020 / Accepted: 13 March 2021 / Published online: 3 April 2021

(c) The Author(s) 2021

\begin{abstract}
This paper describes how an interdisciplinary design team used the Four-Component Instructional Design (4C/ID) model and its accompanying Ten Steps design approach to systematically design a professional development program for teaching differentiation skills to primary school teachers. This description illustrates how insights from a cognitive task analysis into classroom differentiation skills were combined with literature-based instructional design principles to arrive at the training blueprint for workplace-based learning. It demonstrates the decision-making processes involved in the systematic design of each of the four components: learning tasks, supportive information, procedural information, and part-task practice. While the design process was time and resource-intensive, it resulted in a detailed blueprint of a five-month professional development program that strategically combines learning activities to stimulate learning processes that are essential for developing the complex skill providing differentiated instruction in a mathematics lesson.
\end{abstract}

Keywords Instructional design · Cognitive task analysis - Differentiation · Complex skills · Teacher education

Jimmy Frerejean

j.frerejean@maastrichtuniversity.nl

Marieke van Geel

marieke.vangeel@utwente.nl

Trynke Keuning

t.keuning@kpz.nl

Diana Dolmans

d.dolmans@maastrichtuniversity.nl

Jeroen J. G. van Merriënboer

j.vanmerrienboer@maastrichtuniversity.nl

Adrie J. Visscher

a.j.visscher@utwente.nl

1 School of Health Professions Education, Faculty of Health, Medicine and Life Sciences,

Maastricht University, Maastricht, The Netherlands

2 Department of Teacher Development, University of Twente, Enschede, The Netherlands

3 University of Applied Sciences Hogeschool KPZ, Zwolle, The Netherlands 


\section{Introduction}

Today's primary school teachers face an increasing demand for dealing with student diversity. A one-size-fits-all approach in which the teacher presents the same teaching activities to the whole class is being replaced by a differentiated approach. In such an approach, the teacher presents tailored activities to individuals or groups of students to best suit their particular needs (Deunk et al., 2018; Roy, Guay, \& Valois, 2013). This improved fit is why, in most cases, differentiated instruction (DI) is preferred (George, 2005). While the benefits of differentiation are generally well-established, the Dutch Inspectorate of Education reported that teachers in the Netherlands struggle to adapt instruction to student differences (Inspectie van het Onderwijs, 2018). Similar results are reported in international research, giving rise to interventions to improve teachers' differentiation skills (e.g., Eysink, Hulsbeek, \& Gijlers, 2017; Prast et al., 2018; Valiandes \& Neophytou, 2017; Wan, 2017). Spurred by these findings, a design team consisting of researchers from the University of Twente and Maastricht University in the Netherlands set out to design and implement a professional development (PD) program aimed at developing teachers' DI skills in the context of mathematics lessons. A challenging undertaking for two reasons.

Firstly, providing DI constitutes an inherently complex task. There is no simple procedure where following fixed steps guarantees effective differentiation. Instead, teachers need well-honed analysis and decision-making skills based on knowledge of curriculum content and student characteristics, and a flexible attitude to deal with changes on the spot (Van Geel et al., 2019). Teaching such complex skills is not straightforward and requires a well-designed program aimed at the integration of knowledge, skills, and attitudes, as well as the coordination of constituent skills (Janssen-Noordman et al., 2006; Van Merriënboer, Kirschner, \& Kester, 2003). As the development of complex skills takes time, a longitudinal PD program that stimulates learning and practice in the workplace seemed most suited. Secondly, it was unclear which specific content should be taught. A description of providing effective DI at expert level was lacking and no clear standards for good differentiation were known at the start of the design process. The research community is making strong progress in identifying effective operationalizations of DI, such as ability grouping (e.g., Saleh, Lazonder, \& De Jong, 2005; Whitburn, 2001) or creating collaborative learning settings (e.g., Eysink et al., 2017), but effective differentiation requires more than just a toolbox full of individual tools (Deunk et al., 2018; Prast et al., 2018). Consequently, national teacher training institutes often provide piecemeal information or superficial strategies in their curricula. Further analysis was needed to gain insight in the constituent skills required for DI and how they are performed, and which domain-specific knowledge is required for effective decision-making.

To deal with the first challenge of designing instruction for complex skills, a task-centered instructional design model was chosen that stresses working with authentic tasks and stimulates practice in the workplace (Francom, 2016). This Four-Component Instructional Design (4C/ID) model by Van Merriënboer (1997) has a strong foundation in research and its application is described in various contexts (Frerejean et al., 2019), such as teacher training (Kreutz, Leuders, \& Hellmann, 2019), medical education (Maggio et al., 2015), communications training (Susilo et al., 2013), technical training (Sarfo \& Elen, 2007), and information problem solving (Wopereis, Frerejean, \& Brand-Gruwel, 2015). The 4C/ID model states that educational programs can be described using four components: a backbone of learning tasks based on authentic professional tasks, supportive information describing how to approach the tasks and how the domain is organized, procedural 
information describing step-by-step procedures to perform routine aspects of the tasks, and part-task practice for repetition of aspects that need to be highly automated (Van Merriënboer \& Dolmans, 2015; Van Merriënboer et al., 2003).

Dealing with the second challenge of not knowing what expert-level DI entails, required a thorough content and task analysis to yield insight into the way experts perform DI. The 4C/ID model is accompanied by a ten-step process (Ten Steps; Van Merriënboer \& Kirschner, 2018) that guides instructional designers in performing such analyses to uncover the required knowledge, skills, and attitudes and explains how to use these outcomes to inform the subsequent training design according to 4C/ID principles. This process of designing courses based on extensive content or task analysis is illustrated by Vandewaetere et al. (2015), who describe the application of the Ten Steps for the design of five blended learning modules in medical education, and Tjiam et al. (2012), who describe the design of a simulator-based training for surgical skills using 4C/ID based on a cognitive task analysis (CTA) of expert task performance. Yet, literature on how to design a PD program based on theoretical insights as well as empirical analysis of expert performance in practice, is scarce. Therefore, this paper addresses the question: How can instructional design teams design a PD program aimed at teaching relatively unfamiliar complex skills in the workplace? It does this by describing an example of the application of the Ten Steps and the 4C/ ID model in the domain of teacher PD.

A design process is highly dynamic. Activities are not carried out in a linear fashion, but often occur in parallel or are continually revisited, and findings are used to shape, refine, and correct the design in many iterations. However, this text must provide a linear description of this process. The second section begins with a description of the design team. The third section then describes the Ten Steps and the cognitive task analysis. The fourth section explains how the outcomes of the analysis informed the design of each of the training components. The fifth section then presents the final blueprint and discusses issues of motivation and affect. The paper concludes with a discussion and conclusion to reflect on strengths and weaknesses of the blueprint as well as the design process.

\section{Design team}

The PD program was designed and developed by a design team consisting of the researchers and authors of this paper (henceforth: we). Three members are experts in data use in schools, assessment, teacher professionalization, professional collaboration, teaching quality, school improvement, and educational effectiveness, and the others are experts in (fourcomponent) instructional design and innovative curricula. We recruited one person with experience in leading teacher PD programs for the role of co-developer and coach. This coach played an active role in the delivery of the program and was responsible for ensuring the feasibility of the implementation. We used our network of school inspectors, educational consultants, school boards, and teacher training institutes to select nine teachers in the Netherlands that were regarded as experts in providing DI. In addition, 10 experts on DI subject matter were selected, consisting of three school inspectors, four educational consultants, one teacher trainer, and two researchers from other institutes. These two groups were recruited to assist in providing the information necessary to develop the PD program. 
The PD program would be offered in primary schools in the Netherlands to teachers of varying ages and levels of teaching experience. We expected that the academic coaches (internal supervisors of teachers) and the school leaders would also be present at selected meetings during the training.

\section{Approach}

\section{Ten Steps}

The Ten Steps approach by Van Merriënboer and Kirschner (2018) lists 10 design activities that result in an educational blueprint describing the program in terms of the four components. Table 1 shows an overview of the four components of the 4C/ID model, their essential learning processes, and the corresponding Ten Steps approach. The four components in the 4C/ID model are designed to stimulate four learning processes that are essential for complex learning.

Inductive learning refers to constructing cognitive schemas from varying concrete experiences or examples. This is achieved by designing learning tasks (component 1) that require an integration of knowledge, skills, and attitudes and coordination of constituent skills. These whole tasks are similar to tasks that occur in professional practice. Elaboration refers to the construction of cognitive schemas by linking new knowledge to existing prior knowledge. This is done by studying supportive information (component 2), often called 'the theory', which is traditionally presented in lectures, workshops, books, or other kinds of (multimedia) learning materials. Elaborate cognitive schemas are necessary to perform nonroutine aspects that are different in every task. They allow teachers to reason in the domain, to make well-informed decisions, and to flexibly solve problems. In contrast, rule formation is a process in which cognitive rules are formed for routine aspects that are similar across different tasks. These if-then constructions ensure that similar responses are correctly executed in similar contexts. This contributes to schema automation. Procedural information (component 3) stimulates this process by presenting concrete step-bystep instruction just at the time the routine needs to be performed. Finally, a process of strengthening is stimulated for routines that are expected to be carried out automatically without cognitive effort. Repeated part-task practice (component 4) enables this process in which routines are drilled to automaticity. For a more extensive description of the model, see (Van Merriënboer, 1997, 2019; Van Merriënboer et al., 2003).

In Table 1, steps 1, 4, 7, and 10 (printed in bold) refer to the design steps for the four main components. Steps 2-3, 5-6, and 8-9 describe additional activities that inform the design of these four components. These auxiliary steps were integrated in a cognitive task analysis (CTA), consisting of detailed observations and in-depth interviews with experts to uncover the skills they perform, the knowledge they possess, how they apply this knowledge, how they approach problems, and how they reason (Clark et al., 2008).

\section{Cognitive task analysis}

As the CTA in this project is described in detail by Van Geel et al. (2019), only a brief description is presented here. Based on a first literature study, classroom observations with semi-structured interviews were organized among the nine teachers to determine the DI activities in real classroom settings. Through open-ended questions and the reviewing of 


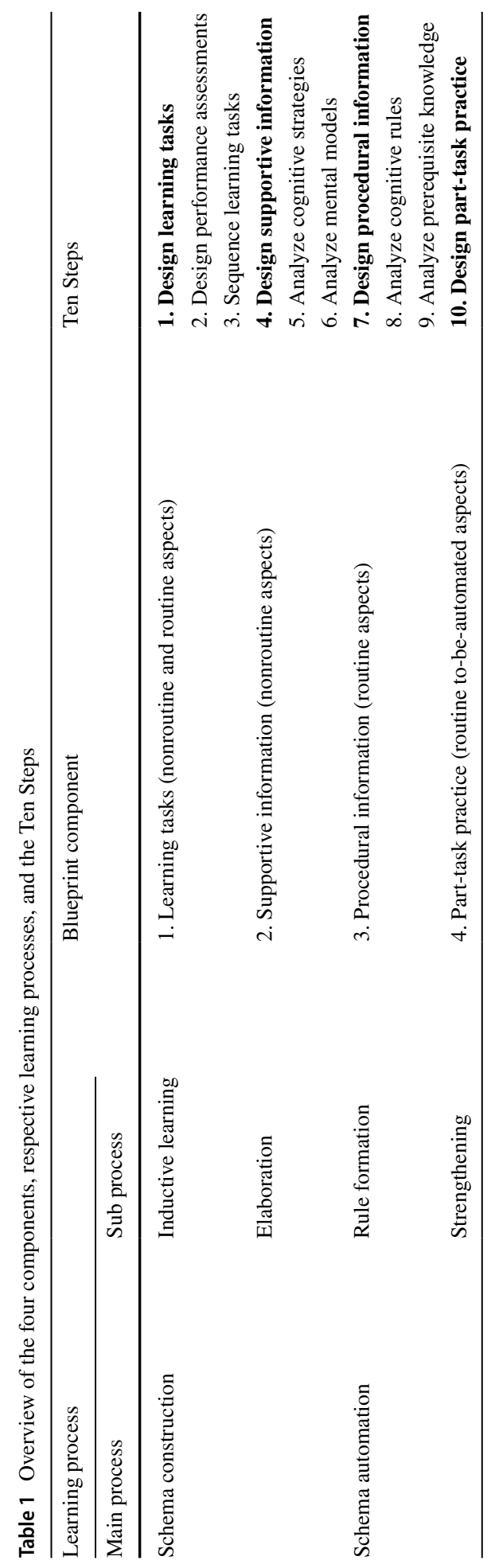


short video clips from the classroom recording, we attempted to reconstruct the teacher's approach in detail. All interviews were recorded and transcribed for further study. This provided a first overview of the whole task of providing DI in a mathematics lesson and the knowledge, skills, and attitudes to carry it out, which formed input for the creation of learning tasks (i.e., Step 1). The whole task was subsequently broken down into constituent skills to create a skill decomposition and performance standards. This provided input for creating performance assessments (i.e., Step 2). Using probing questions, we elucidated cognitive strategies that describe the phases experts go through when they approach a task, including the main decision-making points and rules of thumb that can help to perform each phase (i.e., Step 5). Additionally, experts were asked to define the domain knowledge they used for reasoning and decision-making (i.e., Step 6) and point out how they performed the routine aspects and skills that recur frequently during DI (i.e., Steps 8-9).

To validate and refine the preliminary outcomes, the expert teachers were collectively invited to an expert meeting. After a round of revisions, a group consisting of ten subjectmatter experts was invited for a day-long outcome validation session, during which feedback was collected in several rounds and sub-group activities to improve and expand upon the intermediate products. This meeting was followed by deliberation in the design team, leading to more refinements in the design.

\section{Outcomes}

This section describes the outcomes of the analysis, how they led to the design of the four main blueprint components, and how these components were combined to create the final blueprint for the program. The outcomes are presented step-by-step but note that the actual design process was much more dynamic and iterative.

\section{Step 1: Design learning tasks}

This step describes the design of the backbone of the educational program: learning tasks that are based on real-life professional tasks and that allow the learner to practice all the nonroutine and routine aspects simultaneously. In this design, learning tasks revolved around providing DI in a mathematics lesson in a primary school classroom. The design of these of learning tasks was based on the CTA and on guidelines in the literature on the quality of teacher PD programs (see Borko, 2016; Borko, Jacobs, \& Koellner, 2010; Darling-Hammond, Hyler, \& Gardner, 2017; Desimone, 2009; Garet et al., 2001; Penuel et al., 2016; Timperley, 2008). These context-specific guidelines complemented the generic guidelines presented by 4C/ID and led to several design decisions early in the process.

Firstly, we decided that the program should be school-based and involve teachers, supporting staff, and the school leader to allow for close collaboration, community-forming, discussion, and coaching among fellow teachers. This was also beneficial because face-toface time with the teachers was limited. Secondly, based on literature on teacher PD, we decided that learning tasks should engage teachers in meaningful discussion, observation of others, planning of lessons, and practicing skills in the classroom. These guidelines were strongly in line with the task-centered approach advocated by 4C/ID. In addition, learning tasks should represent the range of possible real-life tasks that the teacher may encounter. Finally, the program should be content-focused and address how students learn mathematics, how teachers can diagnose gaps in understanding, and how they can adjust their 
instruction accordingly. Due to practical limitations and the desire to keep the program feasible and scalable, we decided on a runtime of five months.

According to $4 \mathrm{C} / \mathrm{ID}$, learning tasks at the beginning of the program are ideally practiced in a safe learning environment where errors have no serious consequences and where support and feedback can be easily presented just-in-time. We therefore considered creating meticulously planned learning tasks in which teachers could practice DI skills in a simulated classroom with simulated students. But simulated tasks would significantly reduce practical value for the teachers, who would have to transfer the newly learned skills to the professional tasks, their daily mathematics lessons in their own classrooms. Therefore, we focused on workplace-based learning and adopted the daily mathematics lessons as learning tasks. These inherently whole tasks present the full range of variability, require all the necessary skills, and allow daily opportunities for practice.

The downside of using workplace-based learning tasks is that it leaves the design team with very little control over task sequence, complexity, and embedded support and guidance. For example, providing partially worked-out tasks or providing over-the-shoulder coaching is challenging to implement during real-life mathematics lessons in the classroom. To compensate for the lowered support during the learning tasks, we increased support before and after the learning tasks. Three team meetings were planned at the start of the program to prepare teachers for independent practice in their own classrooms. The coach guided teachers in studying video modeling examples and carrying out imitation tasks in which they created period plans and lesson plans based on provided worked-out examples. Teachers also received a reader with materials (i.e., texts, worked-out examples, systematic approaches) and links to the collection of video modeling examples to consult independently before or after learning tasks. In addition, several reflection sessions were planned throughout the program in which the whole team reflected on past learning tasks under guidance of the coach. The supportive materials are described in "Step 4: Design supportive information".

\section{Step 2: Design performance assessments}

According to the experts, effective differentiation required a constant awareness of and emphasis on instructional goals, monitoring of students' current level of understanding in relation to those goals, deliberate selection of teaching activities from an extensive repertoire, effective application of pedagogical and didactical skills to organize and deliver instruction, and strong reflection skills to evaluate the chosen approach. They considered classroom management and direct instruction as prerequisite routine skills that should cost little mental effort so cognitive capacity is free for more complex DI-related activities. This is well aligned to existing models of teacher development describing that novice teachers first focus on the basics of teaching, such as maintaining a safe learning climate, managing the classroom, and providing clear direct instruction. While novices tend to stick to the guidelines and differentiation strategies prescribed by the method at hand, these models describe that more experienced teachers develop advanced teaching strategies and start to deviate from the prescribed approaches by flexibly adjusting instructions to student differences (for an overview, see Van der Lans, Van de Grift, \& Van Veen, 2017).

Experts showed DI activities in four phases: during preparation of the lesson period, during individual lesson preparations, during individual lessons, and in post-lesson evaluations. This four-phase organization formed the core of the PD program: Practicing the integration of these constituent skills, starting with the preparation of a lesson 


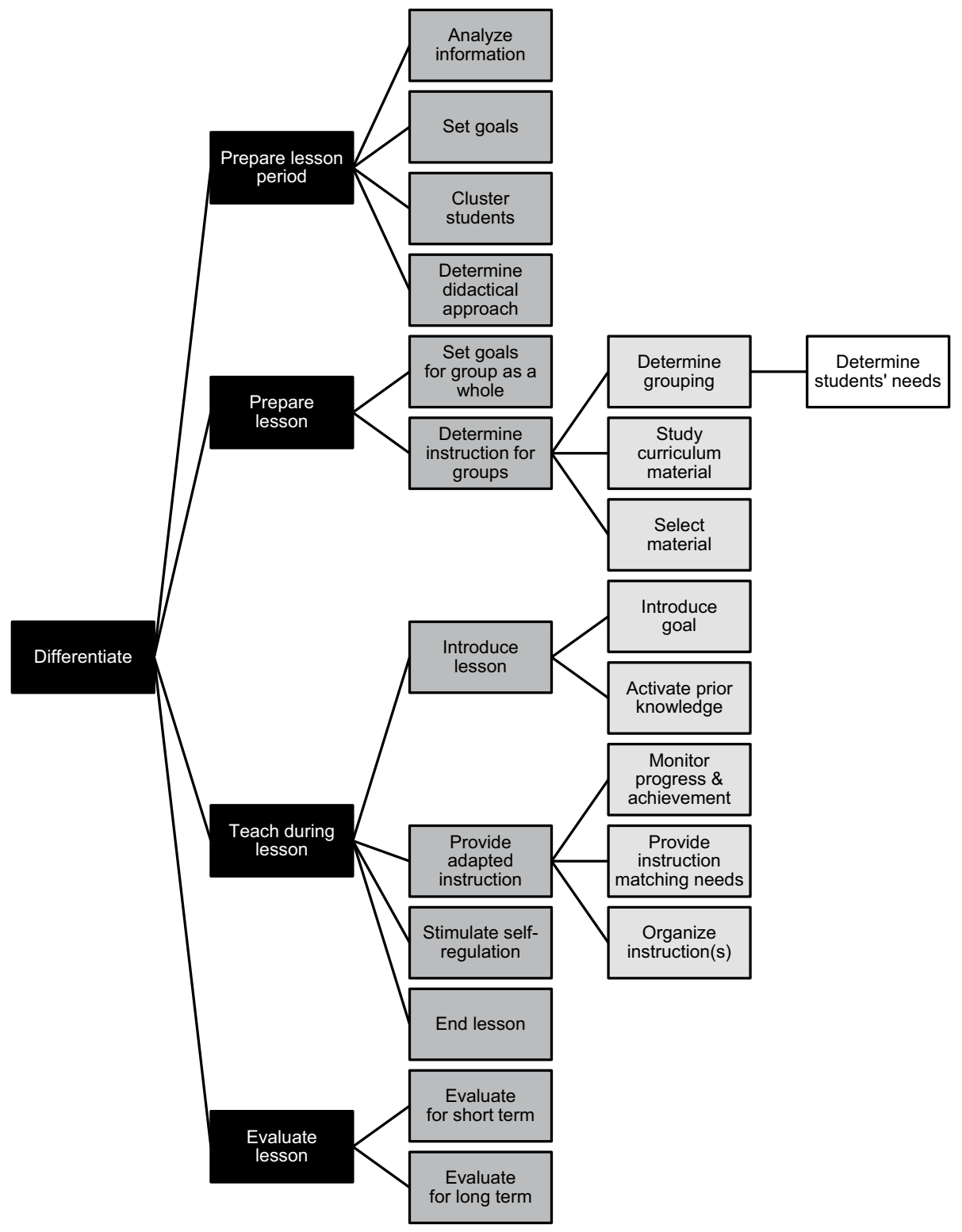

Fig. 1 Skill hierarchy demonstrating hierarchical relation between the skills and their constituent skills addressed in the PD program

period followed by the preparation, execution, and evaluation of individual lessons. The hierarchy in Fig. 1 shows which constituent skills are required (i.e., positioned to the right) for higher-order skills in each of these phases. It is important to note that many constituent skills are highly related, and often depend on the outcomes of other skills in other phases. For instance, the organization of the instruction during the lesson depends largely on information gathered and decisions made in the lesson and period 
preparations-but can still be flexibly adapted on the spot if needed. Due to this high interrelation, practicing the constituents in isolation makes little sense. It is essential that the learners learn how these skills depend on one another and how they can be coordinated to carry out the whole task.

To formulate what learners should be able to do after the program, performance objectives were created for each of the constituent skills. Based on information gathered in discussions with experts and school inspectors, a preliminary list of 30 standards was formulated and converted to a scoring sheet that was made available to the teachers at the start of the training. Each of the 30 standards is rated on a four-point scale ranging from 1 (point of attention) to 4 (excellent). An example standard for preparing the lesson was: The teacher investigates whether the current teaching method provides a fitting instruction for attaining the lesson goals and deviates from the method if necessary. The teacher can justify why the chosen approach is most optimal for attaining the lesson goals and is aligned to the educational needs of the whole group, the stronger students, and the weaker students. Instead of a high-stakes summative assessment at the end of the training, we included multiple low-stakes formative assessments by the coach, who used the scoring sheet to provide structured feedback (Van der Vleuten, 2016; Van der Vleuten et al., 2012).

Teachers also formulated additional personal learning goals at the start of the program for aspects that they felt needed the most improvement. These personal goals were addressed during the feedback sessions (described below) and re-assessed and refined halfway through the program. This added flexibility and a sense of autonomy, as individual teachers may have different personal learning goals (Louws et al., 2017).

\section{Step 3: Sequencing learning tasks}

After designing learning tasks and performance objectives, it was essential to sequence learning tasks in a way that does not overwhelm learners with too much complexity. For this reason, 4C/ID recommends grouping learning tasks together based on their complexity and presenting these groups of tasks in a simple-to-complex order until the most complex tasks can be performed at the end of the program. But in our workplace-based learning approach teachers practice in the classroom during the actual lessons, and we had no control over complexity or task sequence. The usual simple-to-complex sequencing could not be used. In such cases, 4C/ID offers an alternative emphasis manipulation approach, in which learners carry out learning tasks (i.e., their daily mathematics lessons) in their natural complexity, but attention is actively allocated to just an aspect of the task or a certain skill cluster (Choi et al., 2019; Gopher, 2006; Gopher, Weil, \& Siegel, 1989). Comparable to a spotlight illuminating only a part of the stage and keeping the rest in the dark, attention is focused to a specific aspect of the complex task and lowered for the remaining aspects.

This was achieved by directing all activities, supportive materials, and coaching to develop the necessary knowledge and skills for the emphasized aspect. When the teacher reached competency in that aspect, the spotlight moved to a new target and the allocation of the learner's attention was shifted accordingly. The shifting of the spotlight occurred in logical order and repeated until all aspects of the task were addressed at the end of the training (see Frerejean et al., 2016). An emphasis manipulation approach reduces strain on working memory because not all instruction needs to be active in memory at the same time. In this approach, errors may be expected in the aspects that have not yet been emphasized, leading to suboptimal task performance. Despite this, emphasis manipulation can still be used to avoid cognitive overload during task performance. 
Where the term task class in 4C/ID designs commonly refers to a group of tasks of the same level of complexity, in the current design, it refers to a group of tasks that emphasize the same aspect. The aspects that were emphasized in each task class are schematically depicted in Table 2, showing important (combinations of) skills in the rows, and meetings and task classes in the columns. Once a task class was completed, it was assumed that the teacher could perform the emphasized aspect to an acceptable level.

The first group meeting included activities that globally introduced all aspects and provided the learners with an advance organizer for the whole task. Then, emphasis manipulation started. In group meeting 2 the spotlight was on preparing a lesson period (phase 1 in Fig. 1) and on evaluating for the long term. The other aspects of the skill were not addressed at this point. In meeting 3 emphasis was on preparing an individual lesson (phase 2 in Fig. 1). After the group meetings, independent practice started and the focus shifted to DI during the lessons. During the first task class, teachers focused on lesson introductions, lesson endings, and short-term evaluations for the next lessons. They practiced and improved these skills while performing all other aspects as usual. After completing this task class, these aspects were mastered. In the next task class, the emphasis shifted to monitoring progress and achievement. Correspondingly, activities, materials, discussions, and coaching targeted these aspects. Monitoring was an especially important aspect, so it received emphasis again in task class 3 , but combined with adapting instruction. Stimulating self-regulation in students was reportedly one of the most challenging aspects of DI, which is why it was addressed once other aspects were mastered. The schematic in Table 2 demonstrates that all aspects of the differentiation skill have been addressed after finishing the program. While it was not possible to sequence whole tasks, this approach sequences instruction around skill clusters to keep cognitive load under control.

\section{Step 4: Design supportive information}

DI involves a considerable amount of reasoning, problem-solving, and decision-making. To help teachers perform these nonroutine aspects, supportive information was presented that consisted of systematic ways in which tasks in the domain can be approached (i.e., cognitive strategies; Step 5), and the necessary knowledge about how the domain is organized (i.e., mental models; Step 6). Because there were limited ready-made instructional materials available, additional analysis of experts was necessary to uncover these strategies and mental models, and new materials needed to be developed.

\section{Step 5: Analyze cognitive strategies}

The CTA showed that experts moved linearly through certain phases during the preparation of a lesson period and during the preparation and evaluation of a lesson. These cognitive strategies were described in systematic approaches to problem-solving (SAPs) showing a flowchart of the phases and rules of thumb that may help to complete each phase. Figure 2 shows a SAP for preparing a lesson. The SAP shows the main phases of the approach on the left and more specific rules of thumb that serve as heuristics to help the teacher perform phase 3 and 5. Similar SAPs were developed for preparing a lesson period and for evaluating.

In contrast, DI during the lesson hardly showed any recognizable linear phases. Experts' strategies varied and seemed to be dictated by contextual factors such as student needs, school agreements, and available materials. Extensive discussion among experts and the 


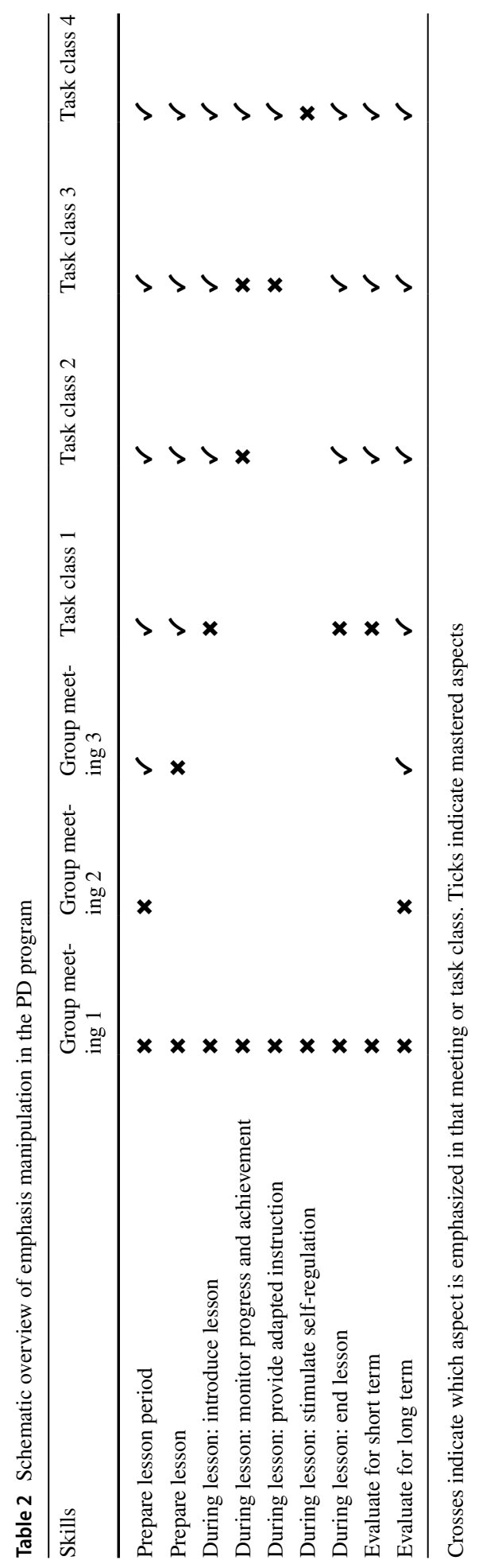




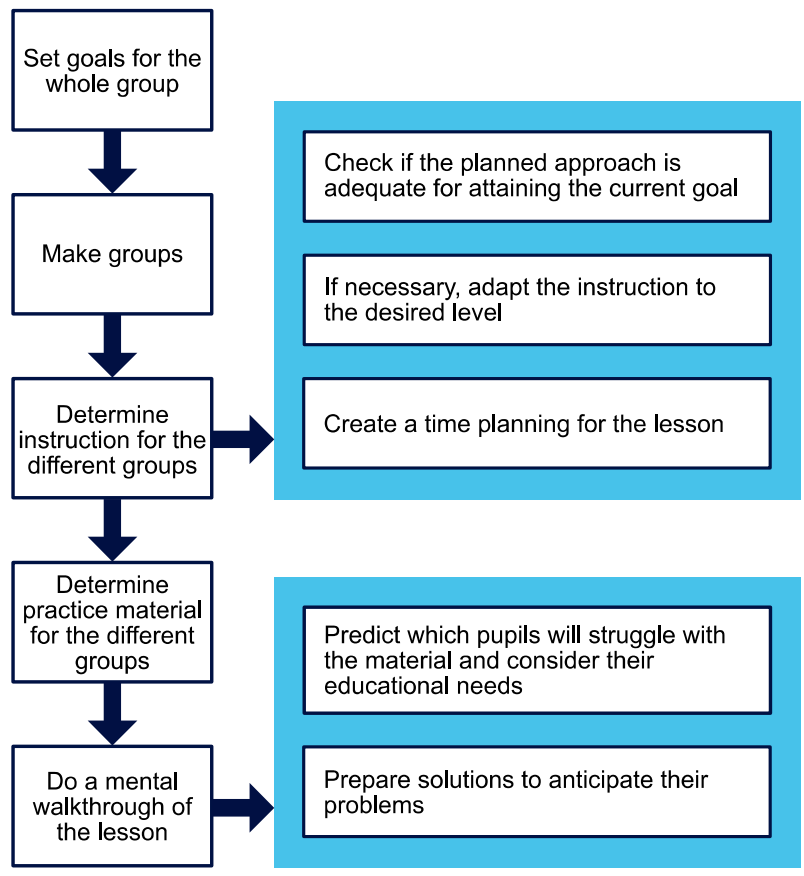

Fig. 2 A systematic approach for preparing a lesson. Main phases are shown on the left with specific rules of thumb displayed for two of the steps

design team revealed that activities during the lesson are governed by five interrelated principles that drive experts' decisions and actions: (1) expert teachers act with the lesson goal in mind, (2) they continuously monitor students' understanding related to the lesson goal, (3) they challenge all students on their own level, (4) they adapt their instruction and practice materials to the students' needs, and ultimately, (5) they stimulate the students' self-regulation behavior. These five principles were depicted in a graphic that also showed the four phases of DI (see Fig. 3).

\section{Step 6: Analyze mental models}

Cognitive strategies to approach tasks are only useful if the teacher can also rely on domain knowledge for reasoning and decision-making. Unsurprisingly, the CTA showed that experts' decision-making is underpinned by an extensive knowledge of the didactics of mathematics. Three important Dutch didactic models were identified that describe students' mathematical development: the hoofdlijnen model, handelings model, and drieslag model; or Four Phase Model of Mathematical Development, CHAT-model, and ProblemSolving Model (Van Groenestijn, 2002; Van Groenestijn, Borghouts, \& Janssen, 2011). These models help teachers determine gaps in understanding and adapt instruction to the student's level. To decide whether and when gaps in understanding should be addressed, teachers require knowledge of the mathematics curriculum and how topics are sequenced in the current year and adjacent years. They also need a strong awareness of the pedagogical and didactical needs of their students. Strategies for eliciting those needs included 
Fig. 3 Nonlinear SAP depicting the five principles that govern differentiation in the four phases

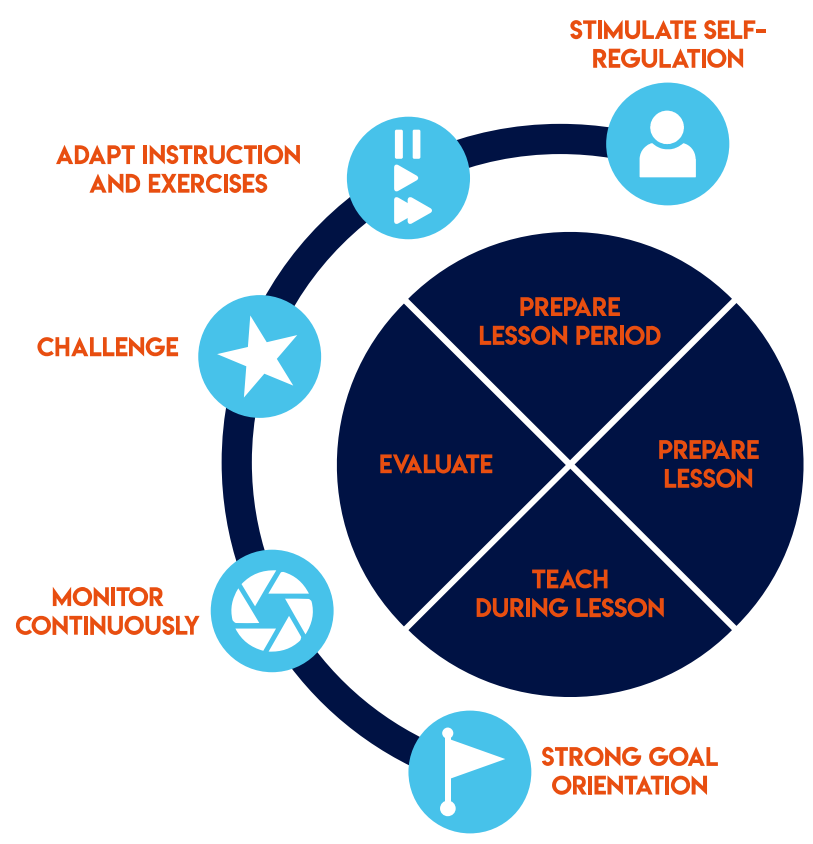

advanced analysis of test results and questioning methods. These were addressed during the group meetings and in an additional reader. Contributions from the expert teachers and subject-matter experts revealed that novice teachers often suffered from misconceptions, for example that DI is equal to personalized instruction, or that adaptive training software takes care of DI. Specific activities were added to the program to explicitly address these misconceptions.

\section{Presentation of supportive information}

After uncovering the strategies and mental models, a variety of supportive materials was created. These included interactive lectures, modeling examples, group discussions, worked-out examples, a reader, and cognitive feedback. Under the emphasis manipulation approach, each task class focused on specific task aspects, so the supportive information was aligned to these aspects. As Table 2 indicates, the program starts with three meetings that focus heavily on elaboration (i.e., developing the necessary cognitive schemas by linking new knowledge to prior knowledge). In the first meeting, the coach introduced the whole task in interactive lectures. In guided group discussions, the school team further elaborated on existing ideas and possible misconceptions about DI. To illustrate cognitive strategies and domain models, multiple modeling examples were studied.

We created these modeling examples by recording expert teachers in their classroom demonstrating DI during the lessons. We added picture-in-picture narrations in which experts explain how the five principles (see Fig. 4) govern the actions and decisions visible on the screen (Frerejean et al., 2018; Van Gog, Paas, \& Van Merriënboer, 2004). Figure 4 shows a screenshot of the classroom recording with narration.

After teachers developed a good understanding of the whole task in the first meeting, the coach zoomed in on the skill preparing a lesson period in the second meeting (cf., 


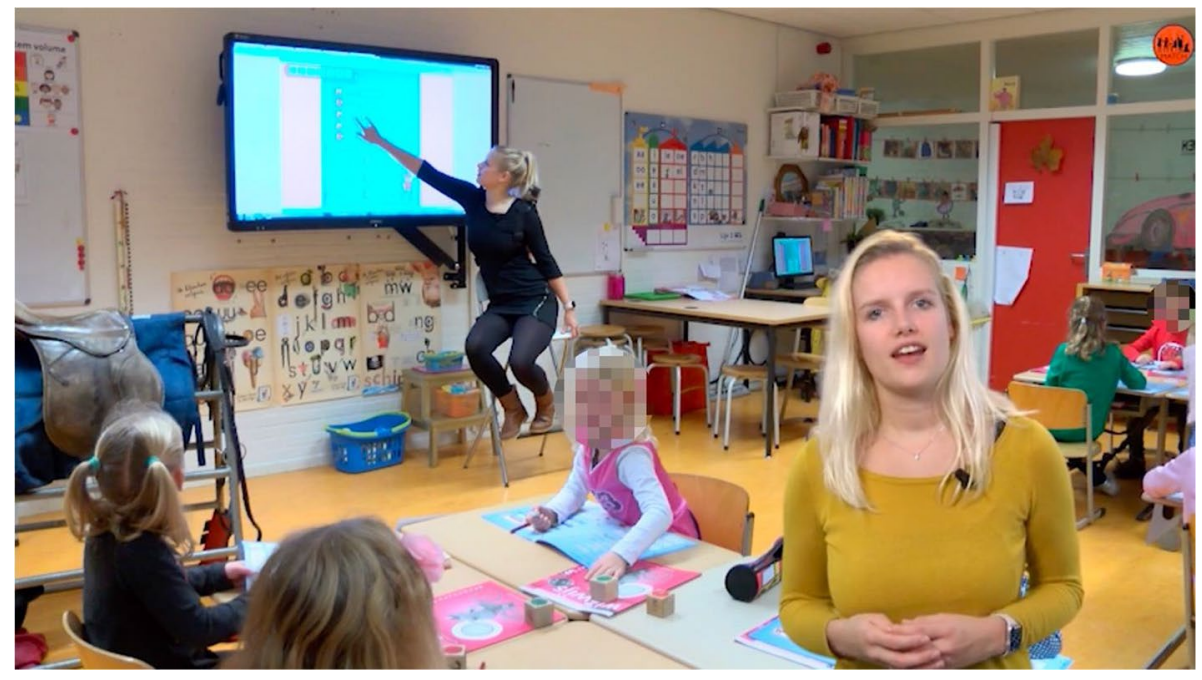

Fig. 4 The video shows a recording of the teacher teaching the lesson while the foreground overlay shows the same teacher commentating on the reasoning behind her actions

the zoom-lens metaphor in Reigeluth's Elaboration Theory (1979)). Relevant SAPs for analyzing test information, setting and formulating period goals, and clustering students were provided in an interactive lecture and demonstrated by studying parts of additional modeling examples. This was accompanied by an imitation task where teachers received a worked-out example of a period plan and were asked to make their own period plans with guidance from the coach. An identical approach was used in the third meeting, but focused on preparing an individual lesson. These first three group meetings were planned in consecutive weeks. Furthermore, modeling examples and worked-out examples of period and lesson plans were made available to the teachers for self-study. Presenting a series of modeling examples allows teachers to compare specific examples in multiple contexts and identify strategies that fit their context best, a particularly effective learning activity (Alfieri, Nokes-Malach, \& Schunn, 2013). Where necessary, the coach also referred teachers to existing documents or manuals regarding didactic models, the interpretation of test reports, or the adaptive training software. After the third team meeting, the series of task classes was initiated, involving extensive independent practice in the classrooms. All task classes followed an identical organization. They started with an introductory lecture, included cognitive feedback during the task class, and ended with a reflection session.

In task class 1, emphasis was on lesson introduction, lesson ending, and reflection for the short term. At the beginning of the task class, the coach provided interactive lectures and teachers were asked to study relevant parts of the modeling examples. During the task class, teachers practiced independently in their own classrooms and could study the provided reader and modeling examples. The coach visited each teacher once in each task class to record and observe the lesson. She assessed the teacher's performance using the scoring sheet to identify omissions and errors in the teacher's approach and provided cognitive feedback with suggestions for improvements. These feedback sessions focused only on the emphasized aspects and the teacher's personal learning goals. Each task class ended with a reflection session in which the full school team was present. Together with the coach, the team reflected on the improvements made thus far, reviewed recordings from that task 
class, and discussed implications for the school climate. Such reflections are essential for forming a professional learning community with school-wide attention to differentiation practices and a strong culture of continuing professional development (e.g., Garet et al., 2001; Timperley, 2008). Exchanging approaches, strategies, knowledge, and experiences may also improve and expand cognitive schemas and teaching repertoires (i.e., stimulate elaboration), which also directly affected the development of strategies for addressing students' educational needs.

Task class 2 emphasized monitoring progress and achievement. In the introductory lecture, the coach introduced relevant SAPs, such as strategies for assessing student work and observing student behavior (i.e., attention, work ethic, etc.) to gauge the student's level of understanding. During the task class, the coach visited one lesson and provided cognitive feedback on the teachers' monitoring performance. In the following reflection session, the school team reflected on teachers' improvement in their ability to monitor student understanding and exchanged experiences. In task class 3, emphasis was on monitoring and adapting instruction to the student's level of understanding, for example by grouping students in specific ways or by providing more concrete or more abstract instruction depending on the needs of the individual or group. Again, this was introduced in a lecture and modeling examples before the task class, evaluated during the task class with an observation and subsequent cognitive feedback, and discussed in the concluding reflection session after the task class. In the fourth and final task class, emphasis was on the most complex activity: teaching students how to self-regulate. The modeling examples, feedback, and reflection session were aimed at teaching how to gradually give students controlled freedom to evaluate their mastery of the lesson goal, to choose whether they want to participate in the instruction, and to choose suitable materials for study.

\section{Steps 7-10: Designing procedural information and part-task practice}

Procedural information helps the learner construct appropriate cognitive rules in long-term memory for the performance of routine aspects. Part-task practice constitutes repeated practice for routine aspects that require a high level of automaticity. The CTA revealed that providing DI is a predominantly cognitive complex task. It is highly flexible and involves a substantial amount of reasoning, decision-making, and problem-solving. The constituent skills shown in the skill hierarchy in Fig. 1 are therefore largely non-routine skills. Yet, some aspects of DI are performed in identical ways across tasks and could be characterized as routines. In fact, we distinguished three types of routine skills. Firstly, we observed that experts were very proficient in classroom management and had many routines to quickly achieve a quiet and attentive atmosphere in which students worked and behaved productively. As teaching classroom management skills would take up valuable time, we decided that classroom management training was outside the scope of this program. Participating schools were informed that teachers should possess at least a basic level of teaching and classroom management skills.

A second category of routine aspects related to using tools or software, such as looking up student data in the school's student tracking system or using adaptive training software. To master these routines, teachers could consult existing manuals or experts in the school or rely on specific workshops provided by the producer of the software. The coach had relevant experience in this domain and was therefore well-equipped to assist teachers with these routines on demand. The third category consists of continually ongoing routines and automated responses to maintain an awareness of what is happening in the classroom 
(Wolff, Jarodzka, \& Boshuizen, 2017, 2020). Knowing where to look and how to "read" whether a student understands the material by interpreting facial expressions and body language might constitute one of these routines. We must note that these routines were not directly reported by the experts during the CTA. When such routines are repeated often, they become automated and are performed without conscious processing. It is therefore not surprising that experts find it difficult to articulate such tacit knowledge (Clark et al., 2008). Whether specific procedural information can be developed to better assist teachers with these routines remains an interesting open question that deserves further research. For now, we relied on the continuous whole-task practice for integrated development of such routines.

To conclude, the procedural information in the program consisted of existing materials for dealing with software and the on-demand step-by-step information provided by the coach. As there was no necessity to repeat skills until they are automated, part-task practice was not included in this program.

\section{Blueprint}

Table 3 shows the final blueprint for the design of the initial group meetings at the start of the PD program, and Table 4 shows a detailed description of one task class. Note that subsequent task classes were identical in organization but only emphasized different aspects of the whole task as described in Table 2 and in the section "Presentation of supportive information". Each task class spanned approximately four weeks. The final task class ended with a group meeting in which school teams shared their experiences and reflect on their overall improvement. This concluded the five-month PD program.

\section{Motivation and affect}

In this section we briefly explore how the current blueprint may affect learners' motivation and emotion through the lens of self-determination theory (Ryan \& Deci, 2000). Selfdetermination theory states that motivation will result from the satisfaction of three psychological needs: competence, autonomy, and relatedness. We believe the current blueprint is effective in fostering feelings of competence. Relevant learning tasks in the own classroom constitute meaningful and useful learning activities that make improvement immediately visible to the teacher. Cognitive overload is avoided by emphasis manipulation and providing sufficient support and guidance. We expect that the emphasis manipulation approach combined with individual coaching will create positive emotions and motivation to keep learning.

Autonomy refers to feelings that success is a result of one's own actions instead of external factors. At first glance, it might seem the program does not provide much autonomy, as all activities are planned in advance. However, teachers formulate personal learning goals that are addressed in the individual coaching sessions. In addition, participating schools are required to show that at least $80 \%$ of the teacher corps is willing to participate in this training voluntarily, meaning that there is sufficient support from the onset. This should contribute to feelings of autonomy and in turn improve motivation.

Finally, motivation is improved if feelings of relatedness are stimulated. The program is placed in the school and frequently stimulates the team to exchange experiences, share feedback, and discuss school-wide best practices. If this collaboration can be sustained it 
Table 3 Overview of the PD program: group meetings

\section{Group meetings}

The program starts with several group meetings in which participants received instruction, studied worked-out examples, such as correctly formulated instructional goals or filled-out lesson preparation formats, and studied modeling examples of an expert differentiating during a mathematics lesson (i.e., illustrating a SAP). In other tasks, teachers worked on creating period plans or lesson plans while being coached.

\section{Supportive information}

- Graphic depicting the phases and principles involved in DI (see Fig. 3)

- SAP for preparing a lesson period

- SAP for preparing a lesson

- Several modeling examples illustrating the SAPs and principles

- Worked-out examples of period plans and lesson plans

\section{Group meeting 1 (week 1)}

First-day introduction. The whole school team is present at this all-day group meeting, containing a series of learning tasks to kick off the PD program. In general, the learning tasks are meant to provide a shared mental model of the whole task of DI with its phases and principles and to address possible misconceptions at the start of the program. At the end of the session, the participants create personal learning goals.

\section{Group meeting 2 (week 2)}

The whole school team is present at this half-day group meeting, containing a series of learning tasks focused on how to prepare for a lesson period.

\section{Group meeting 3 (week 3)}

The whole school team is present at this half-day group meeting, containing a series of learning tasks focusing on how to prepare individual lessons.

\section{Learning task 1.1: shared mental model}

A group brainstorm for developing a shared mental model of DI. Participants create a mindmap of their prior knowledge concerning DI skills, strategies, tools, school rules, etc

\section{Learning task 1.2: modeling example}

The four phases of DI are presented and participants watch segments of a modeling example (see Fig. 4) in which a teacher explains her actions and thought processes during these phases. Segments are interspersed with short group discussions led by the coach

\section{Learning task 1.3: misconceptions}

Using a set of prepared statements relating to frequent misconceptions on DI, the coach engages the group in a discussion to resolve differing perspectives on what DI is and how it should be provided

\section{Learning task 1.4: domain knowledge}

Participants fill out an online survey testing their knowledge on conditions for effective DI, didactics of mathematics and mathematics curricula. The coach discusses the results

Learning task 1.5: modeling example 2

The five principles for effective DI are presented and the coach shows fragments from different modeling examples that illustrate these principles. After each segment, the group is engaged in a short discussion

\section{Learning task 2.1: imitation task}

After an interactive lecture on period preparation, the coach provides guidance and supportive materials to help participants collaboratively perform the activities involved in preparing a lesson period, such as reformulating instructional goals, interpreting test results, identifying educational needs, grouping students, and choosing a didactical approach

\section{Learning task 3.1: modeling example}

Participants watch fragments from a modeling example showing how an expert teacher prepares a lesson, followed by a short group discussion

\section{Learning task 3.2: imitation task}

Similar to task 2.1, the coach introduces and explains the SAP for preparing a lesson and a worked-out example. Teachers collectively follow along, preparing their individual lessons 
Table 4 Overview of the PD program: Task class 1

Task class 1 (weeks 4-8)

After the group sessions, participants have studied several modeling examples and should be competent in preparing lesson periods and individual lessons. In the first task class teachers practice individually in their daily mathematics lessons, focusing only on a subset of the skills: introducing the lesson, ending the lesson, and evaluating for the short term (i.e., the next lessons).

\section{Supportive information}

- Graphic depicting the phases and principles involved in DI (see Fig. 3)

- SAP for preparing a lesson period

- SAP for preparing a lesson

- Several modeling examples illustrating the SAPs and principles

- Worked-out examples of period plans and lesson plans

\section{Learning tasks}

For four weeks, teachers practice the newly learned skills in their daily mathematics lessons. Essential is that teachers learn how to apply the five principles for effective DI while executing these skills.

\section{Procedural information}

Help with using the student tracking system or with adaptive software is available on-demand in the school or from the coach

\section{Supportive information: cognitive feedback}

The coach is present during one of the lessons and provides individual cognitive feedback on the participant's performance in a feedback session at the end of the day, focusing on introducing, ending, and evaluating the lesson.

\section{Supportive information: reflection session}

The task class ends with a group meeting in which the school team shares their experiences and reflects on their improvements and personal learning goals. During this session, the coach also introduces the emphasized aspects of the next task class.

can lead to strong professional communities of practice and catalyze continuous professional development (De Neve \& Devos, 2016; Steinert et al., 2016; Stoll et al., 2006). The direct one-on-one relationship with the coach may contribute to feelings of relatedness as well. To conclude, we are optimistic that psychological needs of competence, autonomy, and relatedness are sufficiently satisfied in order stimulate motivation and positive emotions.

\section{Discussion}

To answer the question of how instructional design teams can design an educational program aimed at teaching unfamiliar complex skills in the workplace, we have demonstrated how the Ten Steps approach can guide a design team through an extensive analysis of expert performance and the design of a 4C/ID-based PD program for in-service teachers. In hindsight, we can reflect on several strengths and weaknesses of the Ten Steps design approach and its product, the blueprint.

Regarding the Ten Steps process, we emphasize that its strength lies in the comprehensive systematic approach and clear guidelines for the design of an effective training program, particularly when the task is still relatively unfamiliar and there are few ready-made instructional materials available. It prescribes clearly which aspects of the complex skill should be analyzed and how these analyses can inform the subsequent design of training components. While other task-centered ID models could have been used, such as cognitive apprenticeship (Brown, Collins, \& Duguid, 1989), elaboration theory (Reigeluth, 1979), or first principles of instruction (Merrill, 2002), they share many characteristics with 4C/ID 
(Francom \& Gardner, 2014). The 4C/ID model stands out as one of the most comprehensive models that is accompanied by an extensive ten-step approach to guide its application. But the Ten Steps should not be mistaken for an easy procedure. It requires considerable investment to ensure the designers are familiar with 4C/ID, the Ten Steps, and approaches to CTA, but also to identify experts in the network and recruit them for participation in the analysis and design. The CTA was a dynamic and iterative process, resulting in many hours of video and audio recordings that required transcription, repeated verification, refinement, and integration. Creating a shared understanding of continually changing data and consulting various stakeholders was highly demanding in terms of time and resources. The design and development of this five-month program spanned nearly two years.

Another weakness pertains to the scope of the Ten Steps. It provides a comprehensive manual for the design of an effective and efficient training program, but not for all required activities in an instructional design project. For other common activities, such as learner or context analysis, development of instructional (multimedia) materials, implementation in context, stimulating learner motivation, and evaluation, if offers little guidance. Instead, the Ten Steps focus solely on analysis and design and includes advice to use additional models to guide such other design activities.

Turning to the blueprint, we can similarly identify strengths and potential weaknesses. A major strength is that the blueprint is based on an extensive content and task analysis. Not many publications on instructional designs articulate the analysis activities that preceded and informed the design. Presumably, most programs are created in collaboration with subject-matter experts (SMEs) that provide the content. However, relying solely on experts without extensive questioning and analysis carries several risks (Clark et al., 2008). Firstly, SMEs are not always expert performers and might report different understandings and representations of the tasks and the required knowledge and skills than the experts who actually perform the professional task in the field. Secondly, experts have difficulty articulating the decisions they make automatically and unconsciously, potentially leaving out important information that is essential for beginners. Finally, experts might mistakenly project their extensive cognitive schemas onto novice learners and be tempted to prescribe learning activities that are more suited to advanced learners (e.g., problem-solving) instead of activities suited for novice learners, such as studying examples (Kirschner, Sweller, \& Clark, 2006). This paper explicitly illustrates how these risks were mitigated by CTA techniques and by integrating contributions from differentiation experts, school and teacher development experts, teacher trainers, inspection experts and instructional designers to create an effective PD program. The resulting design strategically combines learning activities that stimulate the essential learning processes required for learning a complex skill such as DI.

A second strength is that the design is strongly informed by research and based on available best practices. Firstly, the application of 4C/ID ensures the use of solid educational principles to stimulate complex learning without creating cognitive overload. The current blueprint provides an elaborate example of how 4C/ID principles can be applied to workplace-based learning in a longitudinal program that provides sufficient opportunities to develop complex skills. Secondly, the 4C/ID guidelines were combined with domain-specific guidelines from teacher PD literature (for a review, see: Steinert et al., 2016). Consequently, the current design has many commonalities with other effective PD programs (e.g., Brigandi, Gilson, \& Miller, 2019; Prast et al., 2018; Valiandes \& Neophytou, 2017): The current design places the program within the school, involving not only teachers but also school leaders and supporting staff. It also focuses on relevant content, addressing relevant didactic models, highlighting relevant domain knowledge 
and demonstrating expert strategies. And it is a longitudinal program. Teacher PD programs sometimes take the form of a series of short workshops aimed at a particular strategy or approach. Such short interventions may be effective to raise awareness and teach new content, but the transfer of knowledge and skills to daily practice in the workplace is often not evident. A longer duration is generally associated with higher-quality programs (Stes et al., 2010). The current program instead aims at whole task training that provides teachers with an extensive knowledge base and repertoire of strategies in order to flexibly adopt to changes and make good decisions in unfamiliar situations. The five-month runtime seems to provide ample time to reach the desired outcomes, particularly with daily opportunities for practice, although it must be noted that reaching sustainable improvements and substantive changes to practice might even take one to two years, according to Timperley (2008).

Furthermore, the current program combines some innovative PD approaches. One of which are the video modeling examples that show recordings of real-life expert teachers in their own classroom, demonstrating DI practices in actual lessons. The modeling examples are particularly effective because they do not only show overt teacher behavior, but also reveal covert cognitive processing with an integrated narration by the respective teacher. Additionally, individual coaching is not based on observations, but on classroom recordings that are reviewed together with the teacher and provide strong cues for stimulating self-awareness and reflection. Finally, stimulation of communities of practice plays an important role, as the school team is regularly invited for reflection meetings to exchange experiences and to discuss alignment between teachers across classrooms.

We can also identify several points where we believe the program might be improved during future iterations. Most notably, it was indicated earlier that novice and experienced teachers can differ significantly in terms of prior knowledge and learning needs. The program is designed for teachers who have achieved an entry level of basic teaching skills, such as classroom management and providing direct instruction. While some flexibility is incorporated in the form of personal learning goals, it might be the case that the program is too demanding for early-career teachers. Somewhat ironically then, the program might be limited in its ability to flexibly differentiate and align to the needs of individual participants. In addition, we noted that the current program characterizes DI skills as predominantly nonroutine and subsequently focuses strongly on elaboration and inductive learning to construct elaborate cognitive schemas. The formation and automatization of rules to perform routine aspects receives less attention. Future evaluations should indicate whether the program needs adjustments to address routine aspects of the skill more strongly, and perhaps whether it should include part-task training to drill certain aspects to the point of automated performance. Finally, evaluations of the program should reveal the degree to which it addresses affective and motivational goals, and whether changes are necessary to make the program more pleasant or motivating.

To conclude, the proof of the pudding is in the eating. Previous research claims high effectiveness of CTA-based training (Clark, 2014; Tofel-Grehl \& Feldon, 2013) and such designs are published regularly in medical education (see: Cannon-Bowers et al., 2013; Clark et al., 2012; Tjiam et al., 2012; Velmahos et al., 2004). The current paper translates this approach to the domain of teacher PD. It reports the results of the CTA and how they led to the current blueprint, but actual outcomes in terms of changes in knowledge, skills, and attitudes of the participating teachers, organizational changes in the participating schools, and perhaps students' learning outcomes in the classroom, can 
only presented after future evaluations have taken place. Based on these outcomes and evaluations, areas for improvement can be identified.

\section{Conclusion}

This paper presents the design process and blueprint for a primary school teacher PD program aimed at fostering DI skills. It provides two unique contributions to the existing body of literature on instructional design. Firstly, it shows that the utility of a CTAbased instructional design transfers to domains outside of medical education. Secondly, it adds to the scarce literature illustrating the application of the Ten Steps approach. The guidelines presented in the Ten Steps form an essential tool for creators aiming to develop research-informed and task-centered educational programs. Yet the Ten Steps are comprehensive, and its guidelines are complex. When teaching complex systematic approaches to solving a problem, 4C/ID advises to provide illustrations in the form of modeling examples. This paper aims to be such a modeling example, written for the benefit of those in search of an approach to analyze and teach complex skills.

Funding This research is funded by Netherlands Initiative for Education Research (Nationaal Regieorgaan Onderwijs; NRO), Grant Number 405-15-730-003.

\section{Declarations}

Conflict of interest The authors declare that they have no conflict of interest.

Open Access This article is licensed under a Creative Commons Attribution 4.0 International License, which permits use, sharing, adaptation, distribution and reproduction in any medium or format, as long as you give appropriate credit to the original author(s) and the source, provide a link to the Creative Commons licence, and indicate if changes were made. The images or other third party material in this article are included in the article's Creative Commons licence, unless indicated otherwise in a credit line to the material. If material is not included in the article's Creative Commons licence and your intended use is not permitted by statutory regulation or exceeds the permitted use, you will need to obtain permission directly from the copyright holder. To view a copy of this licence, visit http://creativecommons.org/licenses/by/4.0/.

\section{References}

Alfieri, L., Nokes-Malach, T. J., \& Schunn, C. D. (2013). Learning through case comparisons: A metaanalytic review. Educational Psychologist, 48, 87-113. https://doi.org/10.1080/00461520.2013. 775712.

Borko, H. (2016). Professional development and teacher learning: Mapping the terrain. Educational Researcher, 33(8), 3-15. https://doi.org/10.3102/0013189x033008003.

Borko, H., Jacobs, J., \& Koellner, K. (2010). Contemporary approaches to teacher professional development. In P. Peterson, E. Baker, \& B. McGaw (Eds.), International encyclopaedia of education (3rd ed., pp. 548-556). Elsevier.

Brigandi, C. B., Gilson, C. M., \& Miller, M. (2019). Professional development and differentiated instruction in an elementary school pullout program: A gifted education case study. Journal for the Education of the Gifted, 42(4), 362-395. https://doi.org/10.1177/0162353219874418.

Brown, J. S., Collins, A., \& Duguid, P. (1989). Situated cognition and the culture of learning. Educational Researcher, 18, 32-42. https://doi.org/10.3102/0013189X018001032. 
Cannon-Bowers, J., Bowers, C., Stout, R., Ricci, K., \& Hildabrand, A. (2013). Using cognitive task analysis to develop simulation-based training for medical tasks. Military Medicine, 178(10S), 15-21. https://doi.org/10.7205/MILMED-D-13-00211.

Choi, S., Kim, N., Choi, S., \& Kim, D. (2019). Emphasis manipulation effect in terms of the least-abled sets on cognitive load, transfer, and instructional efficiency. Problems of Education in the 21st Century, 77(2), 228-243. https://doi.org/10.33225/pec/19.77.228

Clark, R. E. (2014). Cognitive task analysis for expert-based instruction in health care. In J. M. Spector, M. D. Merrill, J. Elen, \& M. J. Bishop (Eds.), Handbook of research on educational communications and technology (4th ed., pp. 541-551). Springer.

Clark, R. E., Feldon, D., Van Merriënboer, J. J. G., Yates, K., \& Early, S. (2008). Cognitive task analysis. In J. M. Spector, M. D. Merrill, J. J. G. van Merriënboer, \& M. P. Driscoll (Eds.), Handbook of research on educational communications and technology (3rd ed., pp. 577-593). Lawrence Erlbaum Associates.

Clark, R. E., Pugh, C. M., Yates, K. A., Inaba, K., Green, D. J., \& Sullivan, M. E. (2012). The use of cognitive task analysis to improve instructional descriptions of procedures. Journal of Surgical Research, 173(1), e37-e42. https://doi.org/10.1016/j.jss.2011.09.003.

Darling-Hammond, L., Hyler, M. E., \& Gardner, M. (2017). Effective teacher professional development. Learning Policy Institute.

De Neve, D., \& Devos, G. (2016). How do professional learning communities aid and hamper professional learning of beginning teachers related to differentiated instruction? Teachers and Teaching, 23, 262-283. https://doi.org/10.1080/13540602.2016.1206524.

Desimone, L. M. (2009). Improving impact studies of teachers' professional development: Toward better conceptualizations and measures. Educational Researcher, 38, 181-199. https://doi.org/10.3102/ 0013189x08331140.

Deunk, M. I., Smale-Jacobse, A. E., De Boer, H., Doolaard, S., \& Bosker, R. J. (2018). Effective differentiation practices: A systematic review and meta-analysis of studies on the cognitive effects of differentiation practices in primary education. Educational Research Review, 24, 31-54. https://doi. org/10.1016/j.edurev.2018.02.002.

Eysink, T. H. S., Hulsbeek, M., \& Gijlers, H. (2017). Supporting primary school teachers in differentiating in the regular classroom. Teaching and Teacher Education, 66, 107-116. https://doi.org/10. 1016/j.tate.2017.04.002.

Francom, G. M. (2016). Principles for task-centered instruction. In C. M. Reigeluth, B. J. Beatty, \& R. D. Myers (Eds.), Instructional-design theories and models (Vol. 4, pp. 65-92). Routledge.

Francom, G. M., \& Gardner, J. (2014). What is task-centered learning? TechTrends, 58(5), 27-35. https://doi.org/10.1007/s11528-014-0784-z.

Frerejean, J., Van Merriënboer, J. J. G., Kirschner, P. A., Roex, A., Aertgeerts, B., \& Marcellis, M. (2019). Designing instruction for complex learning: 4C/ID in higher education. European Journal of Education. https://doi.org/10.1111/ejed.12363.

Frerejean, J., Van Strien, J. L. H., Kirschner, P. A., \& Brand-Gruwel, S. (2016). Completion strategy or emphasis manipulation? Task support for teaching information problem solving. Computers in Human Behavior, 62, 90-104. https://doi.org/10.1016/j.chb.2016.03.048.

Frerejean, J., Van Strien, J. L. H., Kirschner, P. A., \& Brand-Gruwel, S. (2018). Effects of a modelling example for teaching information problem solving skills. Journal of Computer Assisted Learning, 34, 688-700. https://doi.org/10.1111/jcal.12276.

Garet, M. S., Porter, A. C., Desimone, L., Birman, B. F., \& Yoon, K. S. (2001). What makes professional development effective? Results from a national sample of teachers. American Educational Research Journal, 38, 915-945. https://doi.org/10.3102/00028312038004915.

George, P. S. (2005). A rationale for differentiating instruction in the regular classroom. Theory Into Practice, 44, 185-193. https://doi.org/10.1207/s15430421tip4403_2.

Gopher, D. (2006). Emphasis change as a training protocol for high-demand tasks. In A. F. Kramer, D. A. Wiegmann, \& A. Kirlik (Eds.), Attention: From theory to practice (pp. 209-224). Oxford University Press.

Gopher, D., Weil, M., \& Siegel, D. (1989). Practice under changing priorities: An approach to the training of complex skills. Acta Psychologica, 71(1-3), 147-177. https://doi.org/10.1016/00016918(89)90007-3.

Inspectie van het Onderwijs. (2018). De staat van het onderwijs: Onderwijsverslag 2016/2017 [The state of education: 2016/2017 Education report].

Janssen-Noordman, A. M. B., Van Merriënboer, J. J. G., Van der Vleuten, C. P. M., \& Scherpbier, A. J. J. A. (2006). Design of integrated practice for learning professional competences. Medical Teacher, 28, 447-452. https://doi.org/10.1080/01421590600825276. 
Kirschner, P. A., Sweller, J., \& Clark, R. E. (2006). Why minimal guidance during instruction does not work: An analysis of the failure of constructivist, discovery, problem-based, experiential, and inquiry-based teaching. Educational Psychologist, 41(2), 75-86. https://doi.org/10.1207/s1532 6985ep4102_1.

Kreutz, J., Leuders, T., \& Hellmann, K. (2019). Professionsorientierung in der Lehrerbildung: Kompetenzorientiertes Lehren nach dem 4-Component-Instructional-Design-Modell. Springer Fachmedien Wiesbaden.

Louws, M. L., Van Veen, K., Meirink, J. A., \& Van Driel, J. H. (2017). Teachers' professional learning goals in relation to teaching experience. European Journal of Teacher Education, 40(4), 487-504. https://doi.org/10.1080/02619768.2017.1342241.

Maggio, L. A., ten Cate, O., Irby, D. M., \& O’Brien, B. C. (2015). Designing evidence-based medicine training to optimize the transfer of skills from the classroom to clinical practice: Applying the four component instructional design model. Academic Medicine, 90, 1457-1461. https://doi.org/10. 1097/ACM.0000000000000769.

Merrill, M. D. (2002). First principles of instruction. Educational Technology Research and Development, 50(3), 43-59. https://doi.org/10.1007/BF02505024.

Penuel, W. R., Fishman, B. J., Yamaguchi, R., \& Gallagher, L. P. (2016). What makes professional development effective? Strategies that foster curriculum implementation. American Educational Research Journal, 44, 921-958. https://doi.org/10.3102/0002831207308221.

Prast, E. J., Van de Weijer-Bergsma, E., Kroesbergen, E. H., \& Van Luit, J. E. H. (2018). Differentiated instruction in primary mathematics: Effects of teacher professional development on student achievement. Learning and Instruction, 54, 22-34. https://doi.org/10.1016/j.learninstruc.2018.01.009.

Reigeluth, C. M. (1979). In search of a better way to organize instruction: The elaboration theory. Journal of Instructional Development, 2(3), 8-15.

Roy, A., Guay, F., \& Valois, P. (2013). Teaching to address diverse learning needs: Development and validation of a Differentiated Instruction Scale. International Journal of Inclusive Education, 17, 11861204. https://doi.org/10.1080/13603116.2012.743604.

Ryan, R. M., \& Deci, E. L. (2000). Self-determination theory and the facilitation of intrinsic motivation, social development, and well-being. American Psychologist, 55(1), 68-78. https://doi.org/10.1037/ 0003-066X.55.1.68.

Saleh, M., Lazonder, A. W., \& De Jong, T. (2005). Effects of within-class ability grouping on social interaction, achievement, and motivation. Instructional Science, 33(2), 105-119. https://doi.org/10.1007/ s11251-004-6405-z.

Sarfo, F. K., \& Elen, J. (2007). Developing technical expertise in secondary technical schools: The effect of 4C/ID learning environments. Learning Environments Research, 10, 207-221. https://doi.org/10.1007/ s10984-007-9031-2.

Steinert, Y., Mann, K., Anderson, B., Barnett, B. M., Centeno, A., Naismith, L., Prideaux, D., Spencer, J., Tullo, E., Viggiano, T., Ward, H., \& Dolmans, D. (2016). A systematic review of faculty development initiatives designed to enhance teaching effectiveness: A 10-year update: BEME Guide No. 40. Medical Teacher, 38, 769-786. https://doi.org/10.1080/0142159X.2016.1181851.

Stes, A., Min-Leliveld, M., Gijbels, D., \& Van Petegem, P. (2010). The impact of instructional development in higher education: The state-of-the-art of the research. Educational Research Review, 5, 25-49. https://doi.org/10.1016/j.edurev.2009.07.001.

Stoll, L., Bolam, R., McMahon, A., Wallace, M., \& Thomas, S. (2006). Professional learning communities: A review of the literature. Journal of Educational Change, 7(4), 221-258. https://doi.org/10.1007/ s10833-006-0001-8.

Susilo, A. P., Van Merriënboer, J. J. G., Van Dalen, J., Claramita, M., \& Scherpbier, A. (2013). From lecture to learning tasks: Use of the 4C/ID model in a communication skills course in a continuing professional education context. The Journal of Continuing Education in Nursing, 44, 278-284. https://doi. org/10.3928/00220124-20130501-78.

Timperley, H. (2008). Teacher professional learning and development. International Academy of Education. Tjiam, I. M., Schout, B. M., Hendrikx, A. J., Scherpbier, A. J., Witjes, J. A., \& Van Merrienboer, J. J. G. (2012). Designing simulator-based training: An approach integrating cognitive task analysis and fourcomponent instructional design. Medical Teacher, 34, 698-707. https://doi.org/10.3109/0142159X. 2012.687480 .

Tofel-Grehl, C., \& Feldon, D. F. (2013). Cognitive task analysis-based training: A meta-analysis of studies. Journal of Cognitive Engineering and Decision Making, 7, 293-304. https://doi.org/10.1177/15553 43412474821.

Valiandes, S., \& Neophytou, L. (2017). Teachers' professional development for differentiated instruction in mixed-ability classrooms: Investigating the impact of a development program on teachers' professional 
learning and on students' achievement. Teacher Development, 22, 123-138. https://doi.org/10.1080/ 13664530.2017 .1338196$.

Van der Lans, R. M., Van de Grift, W. J. C. M., \& Van Veen, K. (2017). Individual differences in teacher development: An exploration of the applicability of a stage model to assess individual teachers. Learning and Individual Differences, 58, 46-55. https://doi.org/10.1016/j.lindif.2017.07.007.

Van der Vleuten, C. P. M. (2016). Revisiting 'Assessing professional competence: From methods to programmes.' Medical Education, 50, 885-888. https://doi.org/10.1111/medu.12632.

Van der Vleuten, C. P. M., Schuwirth, L. W. T., Driessen, E. W., Dijkstra, J., Tigelaar, D., Baartman, L. K. J., \& Van Tartwijk, J. (2012). A model for programmatic assessment fit for purpose. Medical Teacher, 34, 205-214. https://doi.org/10.3109/0142159X.2012.652239.

Van Geel, M., Keuning, T., Frerejean, J., Dolmans, D., Van Merriënboer, J., \& Visscher, A. J. (2019). Capturing the complexity of differentiated instruction. School Effectiveness and School Improvement, 30, 51-67. https://doi.org/10.1080/09243453.2018.1539013.

Van Gog, T., Paas, F., \& Van Merriënboer, J. J. G. (2004). Process-oriented worked examples: Improving transfer performance through enhanced understanding. Instructional Science, 32, 83-98. https://doi. org/10.1023/B:TRUC.0000021810.70784.b0.

Van Groenestijn, M. (2002). A gateway to numeracy. A study of numeracy in adult basic education. CD $\beta$ Press, Centrum voor Didactiek van Wiskunde, Universiteit Utrecht.

Van Groenestijn, M., Borghouts, C., \& Janssen, C. (2011). Protocol Ernstige RekenWiskunde-problemen en Dyscalculie: BAO, SBO. . SO.

Van Merriënboer, J. J. G. (1997). Training complex cognitive skills: A four-component instructional design model for technical training. Educational Technology Publications.

Van Merriënboer, J. J. G. (2019). The four-component instructional design model. . Maastricht University.

Van Merriënboer, J. J. G., \& Dolmans, D. H. J. M. (2015). Research on instructional design in the health sciences: From taxonomies of learning to whole-task models. In J. Cleland \& S. J. Durning (Eds.), Researching Medical Education (pp. 193-206). Wiley Blackwell.

Van Merriënboer, J. J. G., \& Kirschner, P. A. (2018). Ten steps to complex learning: A systematic approach to four-component instructional design (3rd ed.). Routledge.

Van Merriënboer, J. J. G., Kirschner, P. A., \& Kester, L. (2003). Taking the load off a learner's mind: Instructional design for complex learning. Educational Psychologist, 38, 5-13. https://doi.org/10.1207/ s15326985ep3801_2.

Vandewaetere, M., Manhaeve, D., Aertgeerts, B., Clarebout, G., Van Merriënboer, J. J. G., \& Roex, A. (2015). 4C/ID in medical education: How to design an educational program based on whole-task learning: AMEE Guide No. 93. Medical Teacher, 37, 4-20. https://doi.org/10.3109/0142159X.2014. 928407.

Velmahos, G. C., Toutouzas, K. G., Sillin, L. F., Chan, L., Clark, R. E., Theodorou, D., \& Maupin, F. (2004). Cognitive task analysis for teaching technical skills in an inanimate surgical skills laboratory. The American Journal of Surgery, 187(1), 114-119. https://doi.org/10.1016/j.amjsurg.2002.12.005.

Wan, S.W.-Y. (2017). Differentiated instruction: Are Hong Kong in-service teachers ready? Teachers and Teaching, 23, 284-311. https://doi.org/10.1080/13540602.2016.1204289.

Whitburn, J. (2001). Effective classroom organisation in primary schools: Mathematics. Oxford Review of Education, 27, 411-428. https://doi.org/10.1080/03054980125200.

Wolff, C. E., Jarodzka, H., \& Boshuizen, H. P. A. (2017). See and tell: Differences between expert and novice teachers' interpretations of problematic classroom management events. Teaching and Teacher Education, 66, 295-308. https://doi.org/10.1016/j.tate.2017.04.015.

Wolff, C. E., Jarodzka, H., \& Boshuizen, H. P. A. (2020). Classroom management scripts: A theoretical model contrasting expert and novice teachers' knowledge and awareness of classroom events. Educational Psychology Review. https://doi.org/10.1007/s10648-020-09542-0.

Wopereis, I., Frerejean, J., \& Brand-Gruwel, S. (2015). Information problem solving instruction in higher education: A case study on instructional design. In S. Kurbanoglu, J. Boustany, S. Špiranec, E. Grassian, D. Mizrachi, \& L. Roy (Eds.), Information literacy: Moving toward sustainability (Vol. 552, pp. 293-302). Springer International Publishing.

Publisher's Note Springer Nature remains neutral with regard to jurisdictional claims in published maps and institutional affiliations. 